\title{
Heroínas Ocultas: As Históricas Nunca Contadas da Ciência
}

\author{
Marcia Ferreira Cristaldo, Marta Luzzi, Claudia Santos Fernandes, Amanda \\ Raynara Quintana Theodoro, Ariadne Nicoly Mori de Paula, Bianca Fernandes \\ Ribas, Clara Scatena da Silva, Diane Rosa da Silva, Giovanna Mara Paes Franco, \\ Kryslla Barbosa Rocha de Carvalho, Luana Arfux de Castro Nogueira, Alice \\ Barbosa do Couto, Maria Eduarda Alves Barbosa, Nayara Arruda Cunha
}

Instituto Federal de Educação, Ciência e Tecnologia de Mato Grosso do Sul (IFMS)

$$
\begin{gathered}
\text { Campo Grande-MS - Brazil } \\
\text { \{marcia.cristaldo, marta.luzzi, claudia.fernandes\}@ifms.edu.br, } \\
\text { \{amanda.theodoro, ariadne.paula, bianca.ribas, clara.silva, } \\
\text { diane.silva, giovanna.franco, kryslla.carvalho, luana.nogueira, } \\
\text { alice.couto, maria.barbosa2, yan.cunha\} destudante.ifms.edu.br }
\end{gathered}
$$

\begin{abstract}
The researchers found serious issues of inequality in Mato Grosso do Sul in the projects developed in the area of extension and research, which cover gender issues in the area of computing, especially women, who try to enter or are in the area of technology. Often it is attributed to these groups, low aptitude for area. In order to contribute to the reversal of inequalities of opportunities faced by people belonging to stigmatized groups, a book was created that presents children and adolescents to the Women Inventors of Computing, in order to increase, persevere the women who work studying in the field of computing. The book was published with the name "Heroinas Ocultas: as histórias ntnea contadas da ciencia” by Brazil Publishing, with an e-book version.
\end{abstract}

Resumo. As pesquisadoras verificaram sérias questões de desigualdades em Mato Grosso do Sul nos projeto desenvolvidos na área de extensão e pesquisa, que abrangem as questões de gênero na área da computação, especialmente mulheres, que tentam entrar ou estão na área de tecnologia. Frequentemente se atribui a estes grupos, baixa aptidão para área. Com o intuito de contribuir para a reversão das desigualdades de oportunidades enfrentadas por pessoas pertencentes a grupos estigmatizados, foi criado um livro que apresenta para crianças e adolescentes as Mulheres Inventoras da Computação, com intuito de aumentar, perseverar as mulheres que trabalham estudam na área da computação. O livro foi publicado com o nome "Heroínas Ocultas: as histórias da ciência" pela editora Brazil Publishing, com uma versão ebook.

\section{Introdução}

Apesar das melhorias significativas ocorridas nas últimas décadas, a educação ainda não é universalmente disponível, e as desigualdades de gênero ainda persistem. Uma grande preocupação em muitos países diz respeito não somente à quantidade limitada de meninas que frequentam a escola, mas também aos caminhos limitados para aquelas que 
conseguem entras nas salas de aula. Isso inclui, mais especificamente, em como abordar a baixa participação e os baixos resultados de aprendizagem das meninas na educação na área de exatas [Abuzinadah 2017].

O "Efeito Matilda" continua ocorrendo atualmente e por isso é importante falarmos sobre ele. Segundo uma pesquisa realizada pela conceituada editora de artigos científicos, a Elsevier (2020), mulheres tendem a deixar chefias e cargos de pesquisador principal para colegas homem. O pesquisador homem teria maior credibilidade e aceitabilidade no meio científico, favorecendo a obtenção de subsídios e outros incentivos. Esse fenômeno da supressão da participação feminina na Ciência foi descrito em 1968, por Robert Merton, como "Matthew Effect", uma referência à passagem bíblica de Mateus 13:12:

Pensando em ensino-pesquisa-extensão, os projetos realizados pelo Instituto Federal de Educação, Ciência e Tecnologia de Mato Grosso do Sul (IFMS), verificaramse a falta de material acessível para crianças e adolescentes entenderem que existem mulheres da tecnologia que inventaram e estão inventando "coisas" para a humanidade.

Assim, desenvolveu-se um livro com 14 mulheres da área de tecnologia, onde o foco são crianças e jovens que se encontram em idade de desenvolvimento de hábitos literários. Entende-se que o grande ganho do projeto é levar novas perspectivas para a relação dessas crianças e adolescentes podendo mostrar a elas o grande feito por mulheres na área da computação. A iniciativa também funciona como complemento à formação de estudantes da instituição oferecendo a experiência na elaboração, produção e aplicação de técnicas na arte da escrita e literatura.

Este livro ainda vai ao encontro de crescimento de discentes, permanência e êxito de meninas que iniciarão e atuam na área de tecnologia. Ele é utilizado em oficinas, eventos e complementos de conhecimento literário.

\section{Metodologia}

O projeto é composto por 11 estudantes da área de tecnologia e 3 professoras, sendo 1 professora de literatura e 2 professoras da área da computação. Para escrita do livro foi feito um roteiro no qual compreendeu três fases: Atividade Preliminares; Escrita do livro e Montagem do livro e Ilustração.

\subsection{Atividades Preliminares e definição do conteúdo do livro}

Estudos do que é um livro - foram realizadas reuniões para demonstrar como se planeja a escrita e sobre técnicas de ilustrações, também definiu-se: 1. partes físicas - a capa, dorso, folha de rosto, folhas de corpo; 2. variação de formato, tamanho, cor, tipo de capa, tipo de papel, mancha (parte impressa) posição da numeração das páginas; 3 . Falou-se sobre a diferença de conteúdo-cartilha, contos, dicionário, romance, poesia, história, receitas, ciências, religião, bibliografia, biografia etc. 4. E explicou sobre as ilustração-livros com e sem ilustração, tipos de ilustração (colorida, sem colorido; conteúdo; técnica informativa). Nesta etapa de definição do conteúdo: 1. Quais e quantas mulheres seriam descritas. 2. Formato das ilustrações. 3. Quantidade de páginas.

\subsection{Escrevendo o livro}


Primeira Redação - Realizou-se reuniões para leitura dos primeiros rascunhos e visualização dos desenhos das mulheres da tecnologia. Segunda Redação - Revisão das histórias já finalizadas e padronização dos desenhos de todas as mulheres descritas no livro.

O livro mostra um resumo de cada mulher, uma história narrativa de sua vida e invenção, bem como uma ilustração de seu rosto e uma característica de sua tecnologia.

\section{Resultados}

As mulheres descritas no livro foram: Ada Lovelace; Edith Clarke; Hedy Lamarr; Dorothy Johnson Vaughan; Grace Murray Hopper; Margaret Heafield Hamilton; Marie Van Brittan Brown; Dra Shirley Jackson; Marissa Mayer; Glória Guimarães e Katie Bouman.

Neste artigo será mostrado parte do livro (quadro 1), sendo ele completo em apresentação para o público.

\section{Quadro 1. Descrição das mulheres do livro "Inspiradas na Computação",} mostrando os desenhos e um resumo da história de cada inventora.

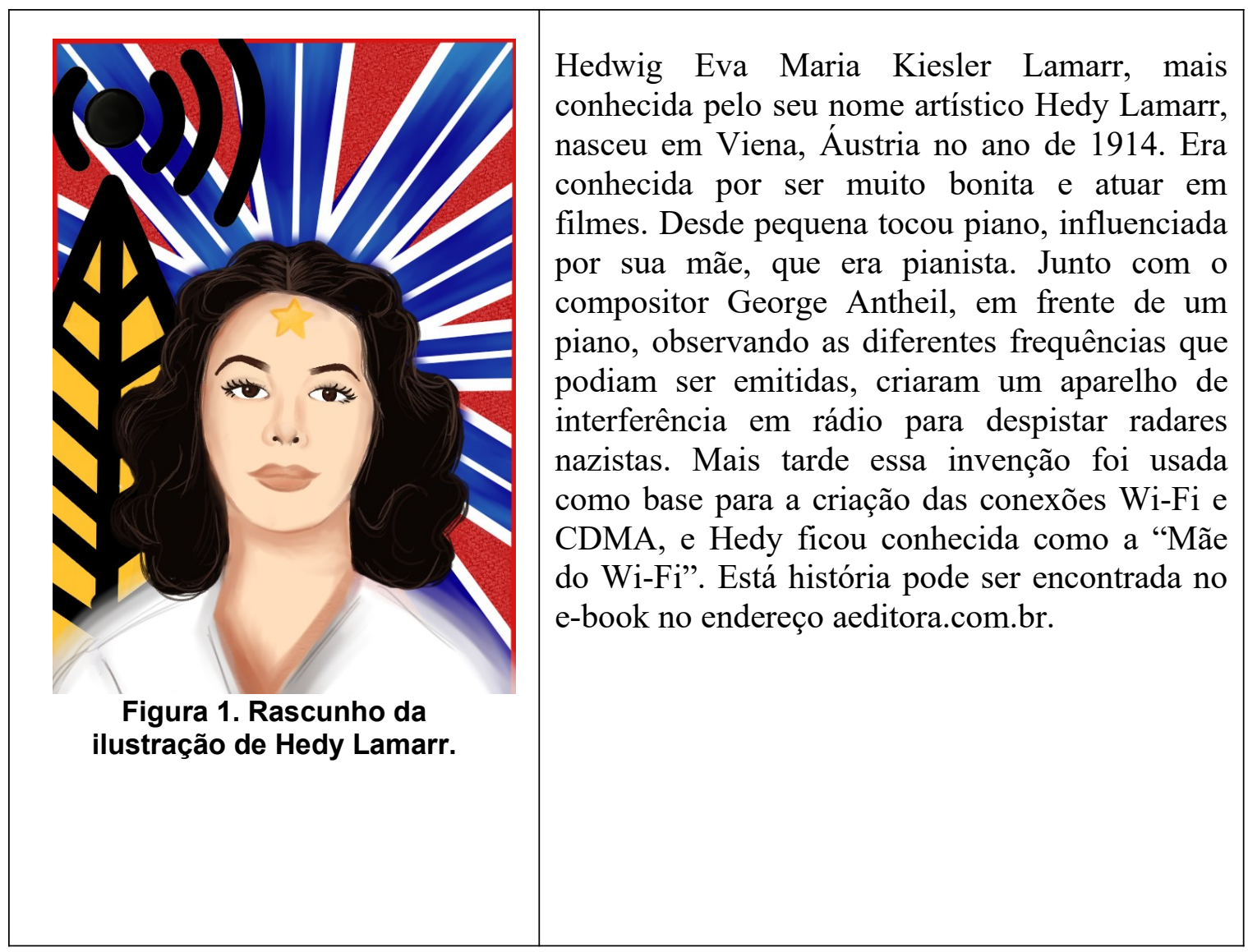




\begin{tabular}{|c|c|}
\hline ão de & $\begin{array}{l}\text { Dorothy Johnson Vaughan cursou Matemática, } \\
\text { trabalhou na Langley Research Center } \\
\text { antecessora da NASA que é situada no Estados } \\
\text { Unidos da América, especializou-se em Rotas de } \\
\text { voos e Programações Matemáticas, tornou-se a } \\
\text { primeira supervisora preta na NASA ao assumir } \\
\text { o comando da West Area Computers, um grupo } \\
\text { formado apenas por mulheres matemáticas } \\
\text { pretas cujos seus cálculos eram usados em } \\
\text { aviação e projetos espaciais. Está história pode } \\
\text { ser encontrada no e-book no endereço } \\
\text { aeditora.com.br. }\end{array}$ \\
\hline $\begin{array}{l}0011001110110 \\
10101011101 \\
0111011111 \\
100100 \\
10111\end{array}$ & $\begin{array}{l}\text { Ada Lovelace é conhecida como a primeira } \\
\text { programadora da história. Nasceu em Londres, } \\
\text { no dia } 10 \text { de dezembro de } 1815 \text {. Com a } \\
\text { influência de sua mãe, despertou cedo o } \\
\text { interesse por matemática e lógica. Ainda jovem, } \\
\text { começou a trabalhar com um matemático } \\
\text { chamado Charles Babbage, em seu projeto sobre } \\
\text { a máquina analítica. Com todo seu } \\
\text { conhecimento traduziu um artigo científico com } \\
\text { anotações próprias que foram chamadas de } \\
\text { primeiro algoritmo. Está história pode ser } \\
\text { encontrada no e-book no endereço } \\
\text { aeditora.com.br. }\end{array}$ \\
\hline $\begin{array}{l}\text { Figura 4. Rascunho da ilustração de } \\
\text { Glória Guimarães. }\end{array}$ & $\begin{array}{l}\text { A brasileira Glória Guimarães formou-se em } \\
\text { Tecnóloga em Processamento de Dados, e MBA } \\
\text { em Gestão Estratégica de Sistemas de } \\
\text { Informação Graduada como Tecnóloga em } \\
\text { Processamento de Dados, com pela Fundação } \\
\text { Getúlio Vargas. É diretora-presidente do Serpro, } \\
\text { acumulando a função de diretora- } \\
\text { superintendente. Desenvolveu carreira na } \\
\text { Tecnologia do Banco do Brasil. Glória também } \\
\text { foi secretária de Logística e Tecnologia da } \\
\text { Informação no Ministério do Planejamento, } \\
\text { vice-presidente de Operações dos Correios. Está } \\
\text { história pode ser encontrada no e-book no } \\
\text { endereço aeditora.com.br. }\end{array}$ \\
\hline
\end{tabular}

As autoras Silva et al. (2019) cita que uso de livros infantis se mostram adequado para a realização de atividades desplugadas pois mostra-se uma melhor 
oportunidade de compartilhar a vida de uma das pioneiras da Computação além de oferecer um contexto para apresentar diversos conceitos computacionais.

As protagonistas do livro estão padronizadas em ordem cronológica, sendo a brasileira Glória Guimarães sem temporalidade com seus feitos realizados, mas está sendo demonstrado que temos entre as nossas brasileiras citadas muitas outras, que serão nosso próximo livro.

A escrita do livro é de uma linguagem de fácil entendimento e com envolvimento nas histórias, onde as leitoras e leitores terão oportunidade de conhecer as criações das mulheres em um contexto compreensível.

Neste contexto, o livro produzido por estudantes e professoras serão entregues para escolas carentes da região em conjunto com oficinas para as meninas interagirem com a tecnologia disponível na instituição.

\section{Conclusão}

As estudantes e professoras trabalham em oficinas com meninas desde 2017, mas sentiam falta de um material colorido, alegre e contado de forma diferente de como eram as mulheres da área de tecnologia. Trabalhando desde o ensino fundamental ao médio verificou-se durante essas oficinas a importância de despertar na criança e adolescente a sensação de segurança, de modo que ela possa acreditar em si mesma e em seus sonhos, e que verdadeiramente eles são possíveis e alcançáveis.

Assim, entre muitas mulheres extraordinárias foram escolhidas 14 grandes mulheres que mudaram o mundo para compor o livro, neste projeto foram envolvidas estudantes de vários cursos da área de tecnologia e professoras de literatura e computação. O livro foi publicado pela editora Brazil Publishing com opção de e-book.

Até a presente data não tem-se publicação relacionada ao livro produzido no Brasil, no qual conta de forma diferente e com entusiamos as criações tecnológicas que usamos hoje. O livro conta como surgiram os talentos delas, quais sonhos elas queiram alcançar e como elas ajudaram a moldar o mundo em que vivemos; o livro é uma poderosa ferramenta para pais e educadores, que mostra aos leitores como se tornarem protagonistas de sua própria história. Cada uma dessas mulheres é fonte de inspiração para a área de tecnologia. No futuro pretende-se contar as histórias das nossas mulheres da computação do Brasil.

\section{Referências}

Abuzinadah, Nihal Esam; Malibari, A. A. K. P. (2017). Towards empowering hearing impaired students' skills in computing and technology. International Journal of Advanced Computer Science and Applications (IJACSA), 8(1).

Elsevier. (2020) "Gender in the Global Research Landscape", https://www.elsevier.com/_data/assets/pdf_file/0008/265661/ElsevierGenderReport final_for-web.pdf, Agosto.

Silvia Bim et al. (2019) "A vida de Ada Lovelace em um circuito de atividades desplugadas". In Anais do XIII Women in Information Technology, (WIT 2029) SBC. 